Original article

\title{
Workplace Stressors and Coping Strategies of Intensive Care Unit Nurses at University Teaching Hospitals, in Rwanda
}

\section{Thomas Munyanziza ${ }^{1 *}$, Busisiwe Bhengu ${ }^{2}$, Emelyne Umutoni Cishahayo ${ }^{3}$, Aline Uwase $^{1}$}

${ }^{1}$ Anesthesia Department, School of Health Sciences, College of Medicine and Health Sciences, University of Rwanda, Kigali, Rwanda

${ }^{2}$ Rory Meyers College of Nursing, New York University, New York, USA

${ }^{3}$ School of Nursing and Midwifery, College of Medicine and Health Sciences, University of Rwanda, Kigali, Rwanda

*Corresponding author: Thomas Munyanziza. Anesthesia Department, School of Health Sciences, College of Medicine and Health Sciences, University of Rwanda, Kigali, Rwanda.Email:tmunyanziza@gmail.com

\section{Abstract \\ Background}

Nursing is widely known as a stressful profession but intensive care unit is the most stressful; when nurses fail to cope with workplace, stresses' complications such as burnout and depression ensue, and this can compromise the quality of nursing care. In Rwanda, there is a limited literature about workplace stress and coping strategies.

\section{Research objectives}

To assess the workplace stress and coping strategies of intensive care unit nurses at University Teaching Hospitals.

\section{Methodology}

This study used a cross-sectional study design, recruited 92 ICU nurses through the census sampling method; ENSS and Brief COPE Inventory, while SPSS was used for data analysis.

\section{Results}

Eighty percent experienced moderate to high stress, while $19.6 \%$ had low stress. Married nurses tend to experience high stress than singles, while those with Bachelors or Master's degree were less likely to be stressed. Main stressors are care for suffering/dying, or agitated patients; and heavy workload, while main coping strategies were alcohol use, emotion support from friends and religion comfort. 


\section{Conclusions}

Nurses experience workplace stress, while workplace stressors are nursing care for suffering/dying or agitated patients and heavy workload. The coping strategies were alcohol use, emotional support and comfort from religion. Rwanda J Med Health Sci 2021;4(1):53-71

Keywords: Workplace stressors, coping strategies, intensive care unit.

\section{Introduction}

Stress is a physiological and emotional reaction to an extraordinary event resulting from an imbalance between a stressful environment and coping ability of the victim.[1] Nursing is a stressful profession, as $75 \%$ of nurses practice in stressful situations, but the intensive care unit is reported to be the most stressful unit in the health care setting.[1] Most of the nurses in ICU experience workplace stress; the scholars reported that in India, $68.29 \%$ of ICU nurses express a certain level of workplace stress.[2] Similar job stress was reported in Singapore whereby 86\% of ICU nurses experienced workplace stress.[3]

In Sub-Sahara Africa, a study done in Nigeria, found that $44.1 \%$ of nurses reported the high level of workplace stress while the high level of burnout was identified in $42.9 \%$ of respondents and this was reported to endanger the nursing care provided to the patients.[4]
Furthermore, a study done in Tanzania reported that $30 \%$ of participants experienced a high level of workplace stress.[5] This high prevalence of stress among ICU nurses is due to different contributing factors[6].

The main factors that contribute to the development of stress among ICU nurses are caring for critically ill patients, particularly emergency cases; a study conducted in South Africa has reported the nursing care for the suffering, dying or critically ill patients as the main cause of severe workplace stress among the ICU nurses.[7]

Besides, a study conducted in Singapore reported that, the workplace stressors were caring for critical traumatic injuries, performing futile care and heavy workload.[7]

Similarly in Ethiopia, evidence showed that the main workplace stressor was to care for patients at end stage of organ diseases, especially when suffering or dying 
.[3] Moreover, the dysfunction of ICU equipment and a heavy workload were reported to be the most stressors elements in intensive care settings.[1] This information highlights the need of having enough working staff and the well-functioning equipment's in ICU to allow nurses working easily and avoid stress negative effects.[1]

Negative effects of stress in ICU are the impairment of nurses' wellbeing and pathologic conditions like anxiety, depression, burnout, and Post Traumatic Stress Disorder.[8] Furthermore, workplace stress can lead to poor quality of nursing care, which may negatively impact the patients' outcomes.[9] Moreover, when workplace stress is not well controlled, it can negatively affect the institution by impairing the normal daily activities, decreasing productivity, increasing absenteeism and turnover among the employees; this information, shows the urgency of exploring the possible causes of job stress and coping strategies.[1]

The coping strategies to curb the workplace stress are identified in the literature; the common coping strategy that are applied by the ICU nurses to control the workplace stress are recreation activities.[8] Other ICU nurses get comfort from religion and spiritual beliefs or alcohol/drug abuse.[10] A study done in Iran reported that $58.3 \%$ of ICU nurses used to read books, newsletters, and magazines, while other ICU nurses used to get emotional support from peers, friends and colleagues.[11]

In Rwanda, a study reported that ICU nurses experience workplace stress while facing a "do not resuscitate order" in the intensive care unit.[12] However, the workplace stressors and coping strategies among ICU nurses are not well explored. This knowledge gap is critical because knowing the level of job stress, workplace stressors and the coping strategies could help in prevention and management of workplace stress in the ICU nurses hence improve the quality of care, patient outcomes and the ICU productivity.

Therefore, there was an urgent need to explore the levels of workplace, stressors and coping strategies in the context of Rwanda.

\section{Methodology}

\section{Study setting}

This study was conducted at three University Teaching Hospitals, namely Kigali University Teaching Hospital (KUTH), King Faisal Hospital (KFH) and Butare 


\begin{tabular}{llll}
\hline University & Teaching & Hospital & nurses at university teaching \\
(BUTH). & & hospitals, in Rwanda were too few \\
& & for random selection.
\end{tabular}

\section{Design}

A descriptive cross-sectional study design was used to assess the workplace stress and coping strategies of the ICU nurses from March to April, 2019.

\section{Population}

The study population was the nurses working in intensive care units (ICUs) in the three mentioned hospitals. To be included in this study, a participant had to be a nurse working in ICU and consenting to be part of the study.

A nurse working in ICU but refusing to consent and other health care providers than nurses were excluded from this study. In total, this study recruited 92 ICU nurses including 48 nurses from KUTH, 17 from BUTH, and 27 from $\mathrm{KFH}$.

\section{Sampling}

A census sampling method (i.e. complete enumeration) in which every unit or everyone in the study population is included in the sample was used. The whole study population constituted the study sample. The rationale for choosing this method, is because the ICU

\section{Data collection tool}

The study used two standard data collection tools, the first being "Expanded Nursing Stress Scale (ENSS) [13]" and the $2^{\text {nd }}$ is the Brief COPE, a tool developed by Carver in 1989 to assess the coping strategies applied by nurses to control the workplace stress.[14] The Expanded Nursing Stress Scale was chosen because it is suitable to assess the stress experienced by nurses during daily nursing practice,[13] while the Brief COPE Inventory was reported to be appropriate to identify the coping strategies applied to cope with the workplace stressors.[15] Permissions to use these data collection tools were obtained by emails from the respective authors.

In addition to socio demographic questions, those tools were merged into one questionnaire and we had a final data collection tool made of three sections. The first section was made of socio-demographic characteristics of participants; the second section included the major workplace stressors (sixteen items from ENSS) and the third section was made of the Brief COPE Inventory composed of seven items.[16] 


\section{Measure}

The ENSS was made of sixteen items scored on 4-point Likert scale, the participant's responses were, 1: never, 2: not at all, 3: sometimes and 4: always. To get the levels of workplace stress, the scores of each participant were summed up then divided by the number of sixteen items to get the mean score of each participant. The participant's level of workplace stress was determined as follows: 1.00 - 1.99 scale: low stress, while 2.00 - 4.00: moderate to high stress.[13] The workplace stressors were reported, according to the number of participants who considered particular workplace stressors to be the cause of stress to him/her.[13]

Furthermore, Brief COPE Inventory was composed of seven items. Each participant responded by choosing the number corresponding to how often he/she applied the particular coping strategy, the frequency of its use was expressed as follows: $1=$ never, $2=$ not at all, $3=$ Most of the time, 4 = Always. A coping strategy was reported according to the number of participants who applied it as a coping strategy to an ICU stress.[16]

\section{Data collection procedures}

The researchers met the unit managers of ICUs to introduce themselves and explain the study purpose and ask permission and appointments to meet the ICU nurses. Thereafter, the researchers met the ICU nurses, explained them the study purpose and requested them to voluntary participate in the study. Those who agreed to be part of the study signed the consent form, following which they were given the questionnaires to complete.

The sealed box was left with the Unit Manager where the participants deposited the completed questionnaires and on weekly basis the researchers opened the box to collect the questionnaires until the end of the data collection period.

To improve the participants' participation in the study, and hence increase the response rate, a reminder was sent by SMS half way and one week before the end of data collection. At the end of data collection period, researchers returned to the study setting to pick up the remaining completed questionnaires. 


\section{Data analysis}

Data were captured and analyzed using the Statistical Package for the Social Sciences(SPSS) version 22. Descriptive statistics (frequency, percentages and cross tabulation of socio-demographic characteristics and levels of workplace stress) and inferential statistic (multinomial logistic regression analysis of sociodemographic characteristics and levels of workplace stress) were computed in this study.

\section{Ethical considerations}

The researchers secured ethical clearance from IRB/CMHS and permissions to collect data were sought from Hospitals' ethics committees. The participants were guaranteed the right to withdraw from the study at any stage without any negative consequences, therefore participation was totally voluntary.

The researchers approached and informed the participants about the research purpose and objectives, procedures involved and their rights regarding the study. To ensure anonymity and confidentiality to participants, the codes were used on questionnaires, which were eventually kept in a locked box and the soft copies were kept confidential and accessible by password only by the authorized researchers.

\section{Results}

\section{Socio-Demographic characteristics of participants and levels of workplace stress}

Half of the participants were younger than 35 years old, $50(54.3 \%)$ were female while $61(66.3 \%)$ were married. Fifty-one participants (55.4\%) had an advanced diploma, while 41 $(44.6 \%)$ held bachelors or master's degrees. Fifty-three percent of participants had more than five years of experience in intensive care unit.

About the levels of workplace stress, 74 (80.3\%) of ICU nurses experienced moderate to high level of workplace stress, while only $18(19.6 \%)$ had the low level of workplace stress. 


\section{Table 1. Socio-demographics of participants and levels of workplace stress $(\mathbf{n}=92)$}

\begin{tabular}{|c|c|c|}
\hline Variables & Frequency & Percent \\
\hline \multicolumn{3}{|l|}{ Age } \\
\hline$\leq 35$ & 46 & 50 \\
\hline$\geq 36$ & 46 & 50 \\
\hline \multicolumn{3}{|l|}{ Sex } \\
\hline Male & 42 & 45.7 \\
\hline Female & 50 & 54.3 \\
\hline \multicolumn{3}{|l|}{$\begin{array}{l}\text { Marital } \\
\text { status }\end{array}$} \\
\hline Married & 61 & 66.3 \\
\hline Single & 31 & 33.7 \\
\hline \multicolumn{3}{|l|}{ Education } \\
\hline \multicolumn{3}{|l|}{ level } \\
\hline $\begin{array}{l}\text { Advanced } \\
\text { diploma } \\
\text { (A1) }\end{array}$ & 51 & 55.4 \\
\hline AO and & 41 & 44.6 \\
\hline \multicolumn{3}{|c|}{ Masters } \\
\hline \multicolumn{3}{|l|}{ Clinical } \\
\hline \multicolumn{3}{|l|}{ Experience } \\
\hline$\leq 5$ years & 43 & 46.7 \\
\hline$\geq 6$ years & 49 & 53.3 \\
\hline \multicolumn{3}{|l|}{$\begin{array}{l}\text { Levels of } \\
\text { workplace } \\
\text { stress }\end{array}$} \\
\hline Low stress & 18 & 19.6 \\
\hline $\begin{array}{l}\text { Moderate or } \\
\text { high stress }\end{array}$ & 74 & 80.4 \\
\hline
\end{tabular}

Workplace stressors and coping strategies as reported by ICU nurses

As presented in Table 2, the main ICU stressors as reported by more than $70 \%$ of participants were nursing care for dying patients in $71(77.2 \%)$, care for suffering patient in 67 (72.8\%), dysfunctional ICU equipment in 69 (75\%) ICU nurses, heavy workload in $65(70.7 \%)$, while fear of doing mistakes during patient care and caring for agitated/violent/ abusive patient/ family were reported by $66(71.7 \%)$.

However, other reported causes of ICU stress are the decision making in absence of doctor 54 (58.7\%), conflicts with doctors 51 (55.4), inadequate emotional preparation to care for critical ill patients/ family and lack of satisfactory answers to patient/ family questions in 56 (60.9\%) and $53(57.6 \%)$ respectively.

Furthermore, the lack of opportunity to express the negative feelings or absence of teamwork and poor salary were the cause of stress were reported in 56 (60.9\%) of ICU nurses, while blames by supervisors were the source of workplace stress in $59(64.1 \%)$ of participants. The absence of doctor in emergency situations or inappropriate medical prescription caused stress in 51(55.4\%), while the lack of experience to ICU equipment was the source of ICU nurse's stress in 59(64.1\%).

Moreover, about the coping strategies as reported by the participants, the most applied coping strategies (in more than 55 
$\%$ of participants) are alcohol/drug abuse in $70(76.1 \%)$, emotional support from friends in 63(68.5\%), turning to other activity to take mind-off and jokes about situation
51(55.4\%); while comfort from religion or spiritual belief was reported in 49(53.3\%). The least applied coping strategies are selfblame and recreation activities that are reported in $27(29.3 \%)$ and $35(38 \%)$ respectively.

Table 2. Workplace stressors and coping strategies as reported by ICU nurses (n=92)

\begin{tabular}{|c|c|c|}
\hline Workplace stressors & Frequency $(n=92)$ & $\begin{array}{l}\text { Percent } \\
\%\end{array}$ \\
\hline $\begin{array}{l}\text { Caring for suffering patient or no improving } \\
\text { patient }\end{array}$ & 67 & 72.8 \\
\hline Care for dying/ dead patient & 71 & 77.2 \\
\hline $\begin{array}{l}\text { Decision making about care in absence of } \\
\text { physician }\end{array}$ & 54 & 58.7 \\
\hline Conflicts with physicians & 51 & 55.4 \\
\hline $\begin{array}{l}\text { Inadequate emotional preparation to care for } \\
\text { patient }\end{array}$ & 56 & 60.9 \\
\hline Lack of answer to patient/family's question & 53 & 57.6 \\
\hline Lack of team work & 56 & 60.9 \\
\hline $\begin{array}{l}\text { Lack of opportunity to express negative } \\
\text { feelings }\end{array}$ & 56 & 60.9 \\
\hline Being blamed by supervisors & 59 & 64.1 \\
\hline Heavy workload and work under pressure & 65 & 70.7 \\
\hline Poor salary or unpaid overtime & 56 & 60.9 \\
\hline $\begin{array}{l}\text { Absence of doctor in emergency or incorrect } \\
\text { prescription }\end{array}$ & 51 & 55.4 \\
\hline Lack of experience with ICU equipment & 59 & 64.1 \\
\hline Fear of doing mistake while patient's care & 66 & 71.7 \\
\hline $\begin{array}{l}\text { Caring for agitated, violent or abusive patient } \\
\text { or family }\end{array}$ & 66 & 71.7 \\
\hline Dysfunctional ICU equipment & 69 & 75 \\
\hline \multicolumn{3}{|l|}{ Coping strategies } \\
\hline Comfort from religion or spiritual beliefs & 49 & 53.3 \\
\hline
\end{tabular}




\begin{tabular}{lll}
\hline $\begin{array}{l}\text { Emotional support from colleagues and } \\
\text { friends }\end{array}$ & 63 & 68.5 \\
$\begin{array}{l}\text { Leisure activities } \\
\text { Self-blames for things that happened }\end{array}$ & 35 & 38 \\
$\begin{array}{l}\text { Turning to other activities to take self-mind off } \\
\text { things }\end{array}$ & 60 & 29.3 \\
Use of alcohol/ drug abuses & 70 & 65.2 \\
Jokes about the situation & 51 & 76.1 \\
\end{tabular}

\section{Factors associated with levels workplace stress of ICU nurses}

This study found that marital status and education level were significantly associated with workplace tress $(\mathrm{p}<0.05)$. Other socio-demographic variables (age, sex, and years of experience) were statistically not significantly associated with the levels of workplace stress. (Table 3).

Table 3. Cross-tabulation of socio-demographic data and levels of stress (n=92)

\begin{tabular}{|c|c|c|c|c|c|}
\hline Variable & & Low stress & $\begin{array}{l}\text { Moderate } \\
\text { or High } \\
\text { stress }\end{array}$ & $\mathrm{Chi}^{2}$ & P value \\
\hline \multirow[t]{2}{*}{ Age } & $\leq 35$ & 11 & 35 & & \\
\hline & $>36$ & 7 & 39 & 1.1 & 0.2 \\
\hline \multirow[t]{2}{*}{ Sex } & Male & 10 & 32 & 0.347 & 0.34 \\
\hline & Female & 8 & 42 & & \\
\hline \multirow{4}{*}{$\begin{array}{l}\text { Marital } \\
\text { status } \\
\text { Education }\end{array}$} & Married & 9 & 52 & 16.01 & $0.01 *$ \\
\hline & Single & 9 & 22 & & \\
\hline & $\mathrm{A} 1$ & 10 & 41 & & \\
\hline & $\begin{array}{l}\text { A0 or } \\
\text { Masters }\end{array}$ & 8 & 33 & 0.001 & $0.049^{*}$ \\
\hline \multirow{3}{*}{$\begin{array}{l}\text { Experience } \\
\text { in years }\end{array}$} & $<5$ years & 10 & 33 & & \\
\hline & $>6$ years & 8 & 41 & 0.6 & 0.4 \\
\hline & $>11$ years & 2 & 12 & & \\
\hline
\end{tabular}

*: p-value statistically significant 


\section{Multinomial Logistic Regression of socio-demographic data and levels of stress}

The logistic regression analysis of levels of workplace stress (dependent variable) and sociodemographic characteristics (independent variables) was done and it shows that marital status and educational level are associated with the levels of workplace stress $(\mathrm{p}<0.05)$. The married experience a high workplace stress $(\mathrm{OR}=2.6)$ in comparison with single ICU nurses; while the ICU nurses with bachelors or master's degree experience low level of workplace stress $(\mathrm{OR}=0.085)$ compared to those with advanced diploma, as shown in Table 4.

Table 4. Logistic Regression of factors associated with workplace stress

\begin{tabular}{|c|c|c|c|c|c|}
\hline \multirow[t]{2}{*}{ Variables } & & \multirow{2}{*}{$\begin{array}{l}\text { Odds } \\
\text { Ratio }\end{array}$} & \multirow[t]{2}{*}{ P. Value } & \multicolumn{2}{|c|}{ 95\% Confidence limits } \\
\hline & & & & Lower & Upper \\
\hline \multirow[t]{2}{*}{ Age } & $\leq 35$ & 1 & & & \\
\hline & $\geq 36$ & 0.5 & 0.3 & {$[-0.5$} & 1.7] \\
\hline \multirow[t]{2}{*}{ Sex } & Female & 1 & & & \\
\hline & Male & 0.495 & 0.35 & {$[-0.6$} & 1.6] \\
\hline Marital & Single & 1 & & & \\
\hline status & Married & 2.6 & $0.001 *$ & {$[0.1$} & $.86]$ \\
\hline \multirow[t]{2}{*}{ Education } & A1 & 1 & & & \\
\hline & A0 or Masters & 0.085 & $0.00 *$ & {$[-0.3$} & $0.9]$ \\
\hline Experience & $\leq 5$ years & 1 & & & \\
\hline in years & $\geq 6$ years & 0.2 & 0.6 & {$[0.04$} & 4.1] \\
\hline
\end{tabular}

*:p -Value statistically significant

\section{Discussion}

\section{Levels of workplace stress}

The present study found that $80.4 \%$ of the intensive care nurses experience the moderate or high level of workplace stress, while $19.6 \%$ reported low level of workplace stress. This prevalence of workplace stress among the ICU nurses is probably caused by the shortage of nurses working in ICU, as the ICU nurse/patients ratio in Rwanda is $1: 2$ while the acceptable is $1: 1$, this shortage increases the workload of the caring nurses.[17] Those findings are consistent with a study conducted in Nigeria which reported that $57.1 \%$ of ICU nurses 
considered the ICU as a stressful unit.[18]

The similarity was reported in Australia, where $87 \%$ of ICU nurses reported a moderate and high level of job stress while a small number experienced low level of workplace stress in the previous month. [19] This is supported by the findings where it was reported that $86 \%$ of residents in hospital experience job related stress during previous month.[20] Another scholar reported that the majority (89.3\%) of ICU nurses experienced moderate to high level of workplace stress in a month before the study, while only few $(11.7 \%)$ of the ICU nurses experienced low level of workplace stress.[19]

Furthermore, the findings of current study were consistent with the study done in Saudi Arabia which reported the big number of ICU nurses ( $88.3 \%$ ) with moderate or high level of workplace stress, while few of them (11.7\%) reported the low level of workplace stress.[19] Another study done in Brazil has found that $78.9 \%$ of ICU nurses were moderately stressed.[21]

The levels of workplace stress were found to be associated with marital status of participants $(\mathrm{P}>0.05)$. This is supported by the findings from a study done in Brazil in 2011
, suggested that the married women experienced the high level of workplace stress than single and men, the reason may be that the women have to balance home and work duties which increases the risk to workplace stress.[22]

The findings of present study suggest that, the workplace stress was negatively associated with education levels of participants, the ICU nurses with bachelors or master's degree experienced low level of workplace stress in comparison with those with advanced diploma $(\mathrm{OR}=0.085)$. This is consistent with the findings from a study done in Brazil, which reported that the professional preparation in continuing education empower the ICU nurses to care for critical patients and other workplace stressors, this consequently decrease the level of workplace stress.[23]

In a study conducted in Nigeria, it was found that the increased work experience negatively correlates with workplace stress, whereby experience overtime in intensive care unit was found to be associated with lower level of stress.[18] The explanation given for this observation was the possibility that, as nurses develop more technical confidence and control over situations of everyday 
practice, thereby becoming more resistant to the stressful events.[18]

This was also reported in a study done in Brazil, which suggested that the length of experience increases the ability of the ICU nurses to adjust and make a better evaluation of their practice, thus mediating the negative impact of stress over work.[24]

However, this association was not statistically significant in our study $(\mathrm{P}>0.05)$. The difference may be explained by the small sample used in this study and the fact that in Rwanda, ICU nurses are not regularly trained. Such trainings would ensure that the ICU nurses become familiar with ICU patient's management and keep updated.[25]

\section{Workplace stressors in ICU nurses}

The present study has found that nursing care for a dying patient or facing the patient death, dysfunction of ICU equipment, nursing care for those suffering or non-improving, caring for ones agitated, violent, abusive patients/families, fear of making mistakes during patient's care and heavy workload are the main causes of job stress in more than $70 \%$ of ICU nurses. Similar findings were reported in a study done in Pakistan, where $66 \%$ of ICU nurses strongly agreed that facing the patient's death was the main source of workplace stress.[26]

In another study done in Brazil, it was suggested that, facing the patient's death or attending a dying patient and caring for the critical emergency cases were found to be the most stressful situation in ICU, the reason may be that patients requiring emergency care and those critically ill with end stage organ conditions usually require the advanced resuscitation techniques and advanced skills which boost the workplace stress.[24]

Furthermore, fear of making mistakes in highly technological and complicated nursing care for the critically ill patients seem to be the source of stress in the Intensive Care Unit.[24] Similar findings were reported in a study done in Saudi Arabia that the nurses in cardiac ICU experience the high level of workplace stress because of advanced nursing care for the critically ill patients that require the high technological equipment in ICU, while other main ICU stressing factor is the heavy workload.[19]

Moreover, a study done in Pakistan has found that, $65 \%$ of ICU nurses strongly agreed that excessive workload is the main cause of workplace stress.[26] This 64 
consistent with the findings of the current study, which suggested heavy workload as one of the main sources of workplace stress.

The dysfunction and unfamiliarity with the ICU equipment were reported as the one of source of workplace stress, the reason may be that with currently increased use of technology in ICU it obligates the ICU nurses to acquire the advanced skills to use the ICU equipment; with limited knowledge and skill, dysfunction of the ICU equipment can constitute stress. The same findings were reported in a study done in Saudi Arabia which suggested that $53 \%$ of ICU nurses strongly agreed that the lack of proper knowledge and training to handle special ICU equipment cause the workplace stress to them.[19]

In addition, the same study done in Saudi Arabia,[19] it was reported that $43.5 \%$ of participants strongly agreed that aggressive and demanding family members were a greater source of workplace stress in ICU. This is very similar to the findings of this study which ranked the nursing care for agitated, violent, abusive patients/families among the first five most important source of workplace stress among the ICU nurses. The reason may be that, when the ICU nurses are assigned to care for agitated patient/families, fear of being insulted or even injured may arise, increasing the level of stress.

The lack of motivation and reward was stated as one of the sources of workplace stress in 47-51\% of ICU nurses.[26] This corroborated the findings of this study, where poor salary or unpaid overtime was reported in $60.9 \%$ of ICU nurses.

\section{Coping strategies to ICU stress}

The findings of the current study indicate that alcohol/drug use, getting emotional/ psychological supports and advices from colleagues and friends, turning to other activities to take mind off and comfort in religion or spiritual beliefs (praying and meditation) are the main coping strategies applied by the ICU nurses to cope with workplace stress as reported by more than $65 \%$ of the respondents. Other reported coping strategies were recreation activities like sport, watching movies / music/ TV, while least used coping strategy is selfblame for things that happened.

This was supported by the findings of a study done elsewhere in which it was reported religion as a common coping strategy, followed by emotional support from friends and colleagues and turning to other activities to take mind-off like watching $\mathrm{TV} /$ movies while the least was self-blame.[19] 
The same findings were reported in other study done in Saudi Arabia has found that the religion is the most occurring coping strategy followed by emotional support from colleagues and friends and use of instrumental support like TV/ movies, while least was the substance abuse and self-blame, the reason of substance/ alcohol abuse as the one of the least applied coping strategy, is that in Saudi Arabia as Arabic country, alcohol is prohibited,[27] which is different from Rwandan setting where the use of alcohol is allowed. The religion is considered as the milestone about coping to and control of stress, particularly in Rwanda as more than $95 \%$ people are affiliated to the religion organization. Furthermore, the use of instrumental support like watching $\mathrm{TV} / \mathrm{music} /$ movies is likely to surface concomitantly with increasing use of technologies.[19] Additionally, the emotional support from friends or colleagues was reported as other common coping strategy applied by the ICU nurses to cope to job stress in Saudi Arabia.[27] This mechanism was similarly reported in the present study, and in a clinical setting it may be judged to relate to team work and multidisciplinary medical care.[27]

\section{Limitations and challenges}

The limitations and challenges that were encountered during the study were that data collection involved the self-filled questionnaire, which was time consuming for the quite busy ICU nurses obliging the researchers to wait for long and regularly remind them.

The sample size was relatively small, so generalizability of the results is limited. Considering that the study was descriptive, the causal-effect relationship could not be established. Finally, the selfreports have a tendency to invite the Hawthorne effect which is responding to impress the researcher rather than presenting the real issues.[28]

\section{Conclusion}

The study assessed the level of workplace stress, job stressors, and coping strategies among ICU nurses at University Teaching Hospitals in Rwanda. The findings of this study showed that $80 \%$ of ICU nurses experience moderate or high workplace stress, while only $19 \%$ experience a low level of workplace stress in ICU.

The workplace stress was found to be associated with marital status and education levels of participants, whereby the married 
ICU nurses tended to experience more stress than the single ones, while the participants with advanced education (Bachelors or Masters) were found to be least stressed than participants with advanced diploma.

The main ICU stressors as reported by participants include nursing care for suffering or unimproving patients, care for the dying, patient's death, nursing care for agitated patients/families, heavy workload, while least workplace stressors are the absence of doctor in emergency situations and conflicts with Physicians. The main coping strategies were the alcohol/drug use, emotional support from colleagues/friends, and comfort from religion.

Based on the findings of the present study on workplace stressors and coping strategies among the ICU nurses conducted at three University Teaching Hospitals, Rwanda, the recommendations are presented as follows:

As the workplace stress was found in most ICU nurses, the health care institutions need to take measures to mitigate the workplace stress by planning for training workshops on workplace stress prevention and control.

As a mitigation of heavy workload was reported in the ICU setting, recruiting of more ICU nurses could improve the nurse patient ratio to the required $1: 1$.

Religious activities should be promoted across the hospitals in Rwanda, as this was found to be a milestone in stress management and prevention. Furthermore, the leisure's infrastructure (rooms) should be in place as this was reported to be the coping strategy that is mostly applied to curb the workplace stress.

Moreover, the ICU nurses should promote teamwork, good communication, mutual collaboration, and interprofessional relationships by discussing their experience with colleagues, friends, nurse leader or spiritual care provider and taking a moment to reflect on one's feelings after the event to enhance coping with workplace stress as this was found to be an effective coping strategy.

\section{Conflict of interest}

The authors declare that there are no known competing financial interests that could influence the work reported in this paper. One of the authors (UA) is supported by the Consortium for Advanced Research Training in Africa (CARTA). CARTA is jointly led by the African Population and Health Research Center and the University 
of Witwatersrand and funded by the Carnegie Corporation of New York (Grant No-B 8606.RO2), Sida (Grant No:54100029), the DELTAS Africa Initiative (Grant No: 107768/Z/15/Z). The DELTAS Africa initiative is an independent funding scheme of the African Academy of Sciences (AAS)'s Alliance for Accelerating Excellence in Science in Africa (AESA) and supported by the New Partnership for Africa's Development Planning and Coordinating Agency (NEPAD Agency) with funding from the Welcome Trust (U.K.) and the U.K. government. The statements made and views expressed are only the responsibility of the Fellow

\section{Authors 'contributions}

TM is the main author of this study, designed the research proposal and wrote the final research project report. BB, EC and AU contributed to this research in data analysis, reviewing and editing before submission.

\section{Acknowledgment}

The authors are thankful to the University of Rwanda, College of Medicine and Health Science, which paid the tuition fees of the corresponding author. Besides, the authors are thankful to the administrators of the three different
Teaching University hospitals, for their collaboration. Finally, The authors are thankful to the study participants for their time and responses.

This article is published open access under the Creative Commons Attribution-NonCommercial NoDerivatives (CC BYNC-ND4.0). People can copy and redistribute the article only for noncommercial purposes and as long as they give appropriate credit to the authors. They cannot distribute any modified material obtained by remixing, transforming or building upon this article. See https:/ / creativecommons.org/licenses / by-ncnd/4.0/

\section{References}

1. Mohamedkheir RA, Amara ZM, Balla SA. Occupational Stress Among Nurses Working in Intensive Care Units in Public Hospitals of Khartoum State , Sudan 2016. Am J Heal Res. 2016;4:166-71.

2. Kumar A, Pore P, Gupta S, Wani A. Level of stress and its determinants among Intensive Care Unit staff. Indian $J$ Occup Environ Med [Internet]. 2016;20:129. Available from: http://www.ijoem.com/text. asp?2016/20/3/129/20313 7

3. Dagget T, Molla A, Belachew $\mathrm{T}$. Job related stress among 
nurses working in Jimma Zone public hospitals, South West Ethiopia: a cross sectional study. BMC Nursing; 2016;1-10.

4. Okwaraji FE, Aguwa EN. Burnout and psychological distress among nurses in a Nigerian tertiary health institution. Afr Health Sci. 2014;14:237-45.

5. Mkumbo KA. Prevalence of and Factors Associated with Work Stress in Academia in Tanzania. Int $J$ High Educ. 2013;3:1-11.

6. Ong YZ. Letter to the Editor The Prevalence of PostTraumatic Stress Disorder in Intensive Care Unit Staff and the Common Coping Strategies Used. J Acad Med. 2013;215-8.

7. Rothmann S, van der Colff JJ, Rothmann JC. Occupational stress of nurses in South Africa. Curationis. 2006;29:22-33.

8. Hafiz A, Ima-nirwana S, Chin K. Comparison of stress levels between physicians working in public and private hospitals in Johor, Malaysia. $J$ Taibah Univ Med Sci
[Internet]. Elsevier Ltd; 2018;492-5. Available from: https://doi.org/10.1016/j.jt umed.2018.01.004

9. Cishahayo EU, Nankundwa E, Sego R, Bhengu BR, Cishahayo EU. Burnout among nurses working in critical care settings : a case of a selected tertiary hospital in Rwanda. Int $J$ Res Med Sci. 2017;5:5121-8.

10. Kathryn L. Mc Cance, Sue E. Huether VLBNSR. Pathophsysiology The Biologic Basis for Disease in Adults and Children, Seventh Edition. Seventh Ed. St. Louis, Missouri; 2016.

11. Laal M. Job Stress Management in Nurses. Procedia - Soc Behav Sci [Internet]. Elsevier B.V.; 2013;84:437-42. Available from:

http://dx.doi.org/10.1016/j .sbspro.2013.06.581

12. Nankundwa E, Brysiewicz P. Lived experiences of Rwandan ICU nurses caring for patients with a do-notresuscitate order. South African $J$ Crit Care [Internet]. 2017;33:19-22. Available from: 
http:/ /www.scielo.org.za/sci elo.php?script=sci_arttext\&p id=S1562-

82642017000100006\&lang= pt\%0Ahttp://www.scielo.org .za/pdf/sajcc/v33n1/06.pdf

13. Kim K., Nam K., Lee E., Jeong G. Validity and reliability of the Korean version of the Expanded Nursing Stress Scale. $J$ fo Acad Nurs Adm [Internet]. 2015;21:542-51. Available from:

https://synapse.koreamed.o rg/DOIx.php?id=10.11111/j kana.2015.21.5.542\&vmode $=$ PUBREADER\#!po=12.5000

14. Carver C, Scheier M, Weintraub J. Assesing coping strategies: a theoretically based approach. $J$ Pers Soc Psychol. 2016;56:267-83.

15. Litman JA. The COPE inventory: Dimensionality and relationships with approach- and avoidancemotives and positive and negative traits. Pers Individ Dif. 2006;41:273-84.

16. Yusoff N, Low WY, Yip $\mathrm{CH}$. Reliability and validity of the Brief COPE Scale ( English version ) among women with breast cancer undergoing treatment of adjuvant chemotherapy: a Malaysian study Reliability and Validity of the Brief COPE Scale ( English Version ) Among Women with Bre. Med $J$ Malaysia. 2010;65:41-4.

17. Babanataj R, Nursing C. Resilience training: Effects on occupational stress and resilience of critical care nurses. Int $J$ Nurs Pract. 2019;1-6.

18. Adeolu JO, Yussuf OB, Popoola OA. Prevalence and Correlates of Job Stress Among Junior Doctors in the University College Hospital, Ibadan. Ann Ibadan Postgrad Med [Internet]. 2016;14:928. Available from: http:/ / www.ncbi.nlm.nih.go v/pubmed/28337094\%OAht tp:/ / www.pubmedcentral.ni h.gov/articlerender.fcgi?arti $\mathrm{d}=$ PMC5354627

19. Alharbi H, Alshehry A. Perceived stress and coping strategies among ICU nurses in government tertiary hospitals in Saudi Arabia: a cross-sectional study. Orig Artic. 2019;39:48-55.

20. Alosaimi FD, Alghamdi AH, Aladwani BS, Kazim SN, 
Almufleh AS. Work-related stress and stress-coping strategies in residents and administrative employees working in a tertiary care hospital in KSA. $J$ Taibah Univ Med Sci [Internet]. Elsevier Ltd; 2016;11:32-40. Available from: http:/ / dx.doi.org/10.1016/j .jtumed.2015.08.009

21. Vivian Aline Preto1 LJP, Act QUE, En AN, Unidades LAS, Intensiva DET, Aline V, et al. Stress among nurses who work at the intensive care unit. Orig Artic. 2009;43:838.

22. Guido LDA, Fernanda G, Pitthan LDO, Umann J. Stress, coping and health conditions. Orig Artic. 2011;45:1427-31.

23. Preto VA, Pedrão LJ. Stress among nurses who work at the intensive care unit. Rev Esc Enferm USP [Internet]. 2009;43:1-8. Available from: http:/ / www.ncbi.nlm.nih.go v/pubmed/20085154

24. Inoue $\mathrm{KC}$ ristin., Versa GL ucinéi. G da S, Matsuda LM isu. Stress level among intensive care nurses in the municipality of Paraná (Brazil). Investig y Educ en enfermeria. 2014;32:69-77.

25. Munyiginya P, Brysiewicz P, Mill J. Critical care nursing practice and education in Rwanda. South African J Crit Care. 2016;32:55-7.

26. Johan S, Sarwar H, Majeed I. To Identify the Causes of Stress among Nurses Working in Intensive Care Unit of Ittefaq Hospital Lahore. Int $J$ Soc Sci Manag. 2017;4:96-109.

27. Isa KQ, Ibrahim MA, AbdulManan $\mathrm{HH}$, Mohd-Salleh ZAH, Abdul-Mumin KH, Rahman HA. Strategies used to cope with stress by emergency and critical care nurses. $\mathrm{Br} J \quad$ Nurs. 2019;28:38-42.

28. Merrett F. Reflections on the Hawthorne effect. Educ Psychol. 2006;26:143-6. 